\title{
Arbuscular Mycorrhizal Fungi Diversity in Two Different Regions in Saudi Arabia
}

\author{
Fahad S. Albaqami*, Saleh A. Sohaibani and Murugan Kasi \\ Botany and Microbiology Department, College of Sciences, King Saud University, \\ P.O. Box 2455, Riyadh 11451, Saudi Arabia \\ *Corresponding author
}

\section{Keywords}

Mycorrhizal diversity, Colonization, Riyadh, Qassim, AMF

Article Info

Accepted:

20 March 2018

Available Online:

10 April 2018

\section{A B S T R A C T}

Plant root endosymbiotic arbuscular mycorrhizal fungi (AMF) are an important functional group of soil microbes in most of the terrestrial ecosystems. Since the desert land is the major covering of Saudi Arabia, the association between AMF and desert plants needs more considerable attention because of their potential importance in agriculture, horticulture, ecology and biodiversity. This study aims to investigate the colonization, composition, diversity and favorable environmental conditions of Saudi Arabian desert habituated AMF in order to explore their agricultural, ecological and biotechnological potential. The total number of collected plants from the three studied areas was 14 plants, represented by 9 unique plants. Seven different plants were collected from Riyadh and Qassim regions. However, five plants (Rumex vesicarius, Echium rauwolfia, Anthemis deserti, Erucaria hispanica and Picris sp.) were collected from both Riyadh and Qassim regions. The most abundant mycorrhizal genus in the collected samples was Glomus as it was found associated with 7 plants collected from different regions with 5 different species. Collected plants from the two different regions showed difference in mycorrhizal colonization rates. The highest hyphal colonization percentage of $75.00 \%$ was found in Picris sp. collected from Qassim region followed by $70.00 \%$ in Picris sp. collected from Riyadh region. The highest vesicles colonization percentages of vesicles were found associated with Echium rauwolfia (36.13\%) plant collected from Riyadh region.

\section{Introduction}

Desert environment is very challenging one for plant life due to the scarce, sporadic precipitation, nutrient deficiency, intense solar radiation, and the high temperature (Apple, 2010). Hence, desert plants show unique reproductive biology, well-adapted ecophysiological, anatomical characteristics, and specialized metabolism and survival abilities. Plant-associated microorganisms are critical components of native desert vegetation in which they are playing an active role in the survival of their plant partners. Soil drought is a widespread problem in the World, which restricts the plant growth and biomass production; particularly in arid and semi-arid regions such as in Saudi Arabia. Drought stress generally occurs when available soil water is reduced and water is continuously lost by the transpiration and/or evaporation as a result of atmospheric conditions. 
Plant root endosymbiotic arbuscular mycorrhizal fungi (AMF; phylum Glomeromycota) are an important functional group of soil microbes in most of the terrestrial ecosystems. In their association with plant roots, AMF improve the plants ability to absorb water and available nutrients via increasing the absorption surface using their hyphae which increases the plant ability to adapt with extreme harsh conditions. Several studies proved the positive effects of AMF colonization on plant growth under drought stress conditions (Herrmann et al., 2016). In turn, plants provide AMF with the carbon they need to survive. AMF are important players in key soil functions such as biogeochemical cycling of essential macronutrients and minerals, and maintenance of soil structure. They also facilitate plant mineral nutrient uptake from the soil and increase plant tolerance to different abiotic stresses (Smith and Read, 2008). Plants associated with AMF exhibit increased nitrogen, phosphorus, calcium, magnesium, and iron uptake, high tolerance to drought, salinity, acidity, and heavy metal stress. Moreover, mycorrhizal plants are more resistant to fungal infections and herbivorous insects comparing to other non-mycorrhizal plants. The possible mechanisms through which AMF could help plants include extensive absorption of water by external hyphae, stomatal regulation through the hormonal signals, greater osmotic adjustment in the mycorrhizal plants that promotes the turgor maintenance even though at low tissue water potentials and the indirect effects of the photosynthetic activity, proline accumulation and increasing the nutritional status in the mycorrhizal plants. Nevertheless, not all the plants showing mycorrhizal symbiosis. More than $15 \%$ of the terrestrial plants are not able to form symbiosis relation with AMF. However, Desert ecosystems mycorrhizal symbioses are of crucial importance since they are essential for native and agricultural plants survival, economically useful desert plants and fungi successful cultivation and their impact on soil carbon dynamics (Apple, 2010).

Saudi Arabia covers roughly $80 \%$ of the Arabian Peninsula which includes the central plateau, range of deserts and mountains as well as dry and marshy coastlands. Majority of Saudi Arabia's land is characterized as arid or semi-arid regions. These areas in nature characterized by several challenging abiotic stresses including drought, salinity, acidity and nutrient deficiency which hinder plant growth and development, reduces their yield and affect their survival. During winter, few places receive occasional showers of rainfall. Depending on this little amount of water, ephemeral plants appear during winter and spring and complete their life cycle overcoming such harsh conditions. The vegetation in Saudi Arabia is very diverse and majority of the plants grow in this arid conditions play a critical role reducing the extent of desertification and soil erosion in the deserts and dry habitats. Moreover, the microorganisms present in these plants rhizosphere micro-environments plays a significant role in their survival. AMF are considered the most important microorganism via their symbiosis relation with the desert plants.

It is not well understood what is the main factors limit the abundance of mycorrhizae in nature. However, different abiotic stresses such as soil drought, salinity, $\mathrm{pH}$ and heavy metal concentration was shown to have significant effect on the composition of AMF communities (Maček et al., 2016). Not all the desert plants have the ability to form symbiotic relationship with AMF (Collier et al., 2003). Previous studies approved the presence of AMF in different sites in Saudi Arabia. A survey conducted among two sites near Riyadh, Saudi Arabia shown that roots of dominant plants like Anisosciadium lanatum, 
Horwoodia dicksoniae, Tripleurospermum auriculatum, Anthemis deserti, Rhazyastricta and Panicum turgidum, showed AMF presence belonging to Glomus fasciculatum and G. mosseeae species. It also noted that among the two, G. mosseeae dominates by alkaline nature of the sand dunes, evidence for mycorrhizal species soil preference. On the other hand, 34 species belong to 20 genera of AMF were isolated from the northern east of Saudi Arabian soil where native truffles are found (Al-Whaibi, 2009). Since the desert land is the major covering of Saudi Arabia, the association between AMF and desert plants needs more considerable attention because of their potential importance in agriculture, horticulture, ecology and biodiversity (Apple, 2010). Moreover, the recognition of mycorrhizal association and distinct host specificity of the AMF are also of significant importance for the documentation of mycorrhizal status. There is a high level of functional diversity in AMF and distinct AMF taxa may have different mycorrhizal functions in an ecosystem. Therefore, the abundance and diversity of AMF is important for assessing soil quality and biological activity in arid and semi-arid areas. In general, there is a vast need for more experimental work for the description and further exploration of the observed mycorrhizal relationship among Saudi Arabian plants. Therefore, the principal aim of the current study is to investigate the colonization, composition, diversity and favorable environmental conditions of Saudi Arabian desert habituated AMF in order to explore their agricultural, ecological and biotechnological potential.

\section{Materials and Methods}

\section{Study sites}

Samples were collected from Rawdat Khuraim in Riyadh region, and Aba Alworood in Qassim region in Saudi Arabia. Seven different plants were collected from Riyadh and Qassim regions. Rawdat Khuraim $\left(25^{\circ}\right.$ $38^{\prime} \mathrm{N}, 47^{\circ} 29^{\prime} \mathrm{E}, 543 \mathrm{~m}$ a. s. 1.) is located about $100 \mathrm{~km}$ northeast of Riyadh in central region of Saudi Arabia. The central physiographic province is mainly dominated by a large central plateau, "Najd", which is divided into "Higher Najd" in the western and "Lower Najd" in the eastern sides. The main features of the central region are Wadi Nisah and Tuwayq mountains. It is characterized by the dissection of its landscape into an extensive system of large wadis which flow eastward, from the higher mountains in the west to the plains of Najd, responding to the general slope of the land. These wadis are not continuous, and at times covered and buried by the sand dunes of Dahna desert. Seasonal springs originate in these wadis during rainy days and often create shallow pools along the banks and depressions. Meteorological data of the central region are characterized by mean air temperature ranging from $10{ }^{\circ} \mathrm{C}$ in January to $42{ }^{\circ} \mathrm{C}$ in July and an annual rainfall from 12 to $36 \mathrm{~mm}$. The mean relative humidity ranges between $10 \%$ and $50 \%$, while the mean evaporation value is $10.35 \mathrm{~mm} /$ day. Aba Alworood ( $27^{\circ} 2^{\prime} \mathrm{N}, 44^{\circ}$ 7' E, $576 \mathrm{~m}$ a. s. 1.) is located about $200 \mathrm{~km}$ northeast of Qassim. Qassim Region is located in the central part of Saudi Arabia, and at the central part of the Saharo-Arabian floristic region. The climate of the Qassim Region is characterized very hot dry summers and mild to cool winters. Mean monthly precipitation is $11.4 \mathrm{~mm}$ with mean monthly air temperature of $15-34^{\circ} \mathrm{C}$. The relative humidity during winter ranges from 14 to $72 \%$, whereas during summer, it ranges from 8 to $31 \%$.

\section{Plant sampling}

Plant sampling was conducted during the flowering stage of the plants. Ten different individuals (replicates) of each plant were collected. Vegetative parts of the ten plants 
were kept in plastic bags for identification. Collected plants were identified according to (Collenette, 1999; Chaudhary, 2001) at the College of Science Herbarium, King Saud University. Root systems of the ten replicates were collected with the maximum care to avoid any damage to the root systems of the different collected plants. Roots were carefully cleaned from the soil particles and put in plastic bags for transferring to the laboratory for further mycorrhizal analysis and DNA extraction. The soils loosely and tightly bound to the surface of roots were removed by clean tweezers and brush, and defined as rhizosphere soil samples for DNA extraction and spore density determination. In the laboratory, the roots were separated from the collected soils and preserved in 50\% alcohol after cleaning and washing.

\section{Root processing and assessment for mycorrhizal colonization}

To evaluate mycorrhizal colonization, the root samples were washed with tap water, and then cut into about 1-cm length segments. A modified method from Phillips and Hayman (1970) was used to clean and stain root samples. The segments were first softened in $2.5 \% \mathrm{KOH}$ at $90{ }^{\circ} \mathrm{C}$ for $1 \mathrm{~h}$, bleached in alkaline hydrogen peroxide at room temperature for $30 \mathrm{~min}$, acidified in $1 \% \mathrm{HCl}$ at room temperature for $1 \mathrm{~h}$, and then stained with trypan blue $(0.05 \%)$ at $90{ }^{\circ} \mathrm{C}$ for $20 \mathrm{~min}$. Stained root segments were mounted on glass slides. To facilitate the observation of different type of mycorrhizal structures, the slide's cover slip was gently pressed after mounting the segments. The mycorrhizal colonization was assessed by direct microscopic observation using digital computerized microscope (Model DP-72, Olympus) at 20x-40x magnification. A root segment was considered to be infected if it showed mycelium, coiled hyphae, vesicles, arbuscules, or any other combination of these structural characteristics of AMF. Data on different structural variables, e.g. colonization rate of fungal structures (mycelium, vesicle, and arbuscules) was recorded for at least 50 root segments for each sample. The mycorrhizal colonization was estimated according to the method described by Trouvelot.

\section{Soil sampling}

Rhizosphere was defined as the soils loosely and tightly bound to the surface of roots. The remaining extracted soils were collected at the depth of $15-30 \mathrm{~cm}$ beneath the plant samples at different directions following the standard sample collection methods and homogenized and then approximately $500-1000 \mathrm{~g}$ soil was placed in plastic bags for determination of soil different physical and chemical characteristics. Ten soil samples were collected for each studied plant (one from the soil under each plant replicate) and kept in plastic bags for transferring to the laboratory for further analysis. In the laboratory, soil samples were sieved using $2 \mathrm{~mm}$ sieves to remove stones, coarse roots and other litter and stored at low temperature.

\section{Soil sample processing of and spore isolation}

AMF spores were isolated from $100 \mathrm{~g}$ of soil samples using wet sieving and sucrose density gradient centrifugation (Gerdemann and Nicolson, 1963). Distilled water was added to $100 \mathrm{~g}$ of soil and the solution passed through a series of ASTM-60 (250 $\mu \mathrm{m})$, ASTM-270 (53 $\mu \mathrm{m})$ and ASTM-400 $(38 \mu \mathrm{m})$ sieves. The soil fraction in the last sieve was collected into plastic tubes. Spore suspensions $(25 \mathrm{~mL})$ were transferred to $50 \mathrm{~mL}$ centrifugation tubes, and another $25 \mathrm{~mL}$ of a $70 \%$ sucrose solution were added at the bottom of the tubes, which were then centrifuged for $2 \mathrm{~min}$ at $3000 \mathrm{rpm}$. Four replications of soil subsamples were used for 
spore counting under the stereo-binocular microscope at $25 \mathrm{x}$ magnification power. The total number of spore population in each individual sample was calculated per $100 \mathrm{~g}$ dry soil basis

\section{Microscopic identification of mycorrhizae}

The obtained spores were separated and segregated by their morphological and molecular characteristics.

The spores were observed under stereobinocular microscope and examined using compound microscope after mounting using a mixture of polyvinyl alcohol in lactoglycerol (PVLG) and Melzer's reagent (1: 1 v: v). The identification of spores was done following standard methods of Schenck and Perez (1990), Schüßler et al., (2001) and Redecker and Raab (2006). The identification process was based on spore's morphological characteristics including color, size, surface ornamentation and wall structure.

\section{Molecular characterization of mycorrhizae}

\section{DNA extraction}

Fine roots and rhizosphere soil were homogenized in liquid nitrogen using ceramic mortar and pestle. Mycorrhizal DNA was extracted from approximately $100 \mathrm{mg}$ lyophilized roots using QIAamp® DNA Mini Kit (QIAGEN Korea Ltd, Korea) following the manufacturer's instructions. The purity and the concentration of the DNA were measured by NanoDrop 2000/2000c UV-Vis (ThermoFisher Scientific, USA), and the quality was checked by agarose gel electrophoresis (Invitrogen, USA) with ethidium bromide staining (Sigma, USA). The DNA samples were then diluted 1: 10 with double distilled water to be used as PCR template.

\section{PCR amplification and DNA sequencing}

Partial AMF 18S ribosomal RNA (about 550 bp) spore DNA extracts was amplified with the universal eukaryotic primer NS31(Simon et al., 1992) and primer AM1, designed to amplify AMF $18 \mathrm{~S}$ ribosomal RNA sequences but not plant sequences (Helgason et al., 1998). The PCR reactions were carried out in a final volume of $25 \mathrm{~mL}$, containing $12.5 \mathrm{~mL}$ $2 \times$ Taq Master Mix (Invitrogen), $0.5 \mathrm{~mL}$ each primer (10 $\mathrm{mM}$, Invitrogen), $1 \mathrm{~mL}$ template and $10.5 \mathrm{~mL}$ RNase-Free Water with the following cycling conditions: $94{ }^{\circ} \mathrm{C}$ for $4 \mathrm{~min}$, followed by 30 cycles of $94{ }^{\circ} \mathrm{C}$ for $50 \mathrm{~s}, 56{ }^{\circ} \mathrm{C}$ for $60 \mathrm{~s}, 72{ }^{\circ} \mathrm{C}$ for $70 \mathrm{~s}$ and extension at $72{ }^{\circ} \mathrm{C}$ for $10 \mathrm{~min}$. All the PCR reactions were run in BioRad PCR cycler (USA). PCR products were examined on a $1.5 \%(\mathrm{w} / \mathrm{v})$ agarose gel with ethidium bromide staining in the presence of DL2000 DNA ladder. PCR products were purified using Universal QIAquick PCR Purification Kit (QIAGEN Korea Ltd, Korea). Purified PCR products were sent for sequencing by Qacrogen, Seoul, Korea.

\section{Phylogenetic analysis}

The obtained DNA amplicons were sequenced, and the obtained sequences were searched for their phylogenetic relationships with other known sequences available in reference databases using MEGA software. The generation of phylogenetic trees was performed using 4 different phases or steps; (1) acquiring the sequences, (2) aligning the sequences, (3) estimating the tree and (4) presenting the tree.

For acquiring the sequences will be used in the tree estimation, each obtained sequence was blasted using blastn (Standard Nucleotide BLAST) against Nucleotide collection (nr/nt) database with default parameters. About 10 different sequences of different species were 
chosen from the blast hits based on their similarity score and query coverage. The range of nucleotides in the subject and the query alignment status (whether query aligns with the subject sequence itself "Strand = plus/plus" or with its complement "Strand = plus/minus") with the subject was noted and the parameters was edited according to this values before alignment step. The obtained sequences were aligned to the sequence of the mycorrhizal sample using MUCSLE algorithm with default parameters. The aligned sequences were saved to a new mega session (.mas) file and exported to a MEGA format (.meg) file to be used in tree estimation. The exported MEGA file containing the aligned sequences was used for the estimation of the Maximum Likelihood (ML) tree. To find the best model for tree estimation Find Best DNA/Protein Models (ML) command was run in the MEGA software and the results was saved to a new excel file. Then, computing of the phylogeny tree was done using the Construct/Test Maximum Likelihood Tree in the software after editing the parameters as follows:

Model/Method: was selected based on the results obtained from calculating the best model for the sequences. Rates among Sites: was selected based on the results obtained from calculating the best model for the sequences to be Gamma distributed $(\mathrm{G})$ or Gamma distributed with Invariant Sites $(\mathrm{G}+$ I). Gaps/Missing Data Treatment: was set to partial deletion in which sites with missing data are removed only as the need arises means that option retains more information. To assess the reliability of that estimate, the bootstrap method was used with 1000 replicates. Finally, the tree was computed. The different calculated trees were represented in Unrooted Rectangular Phylogram format with bootstrap percentages on nodes, indicate the reliability of the cluster descending from that node. The higher the number, the more reliable is the estimate of the taxa that descend from that node. In general, nodes with $<70 \%$ reliability are not taken seriously.

\section{Statistical analysis}

The percentages of different mycorrhizal structures exist on the same plants collected from the different study sites was compared using T-test at significance level $P \leq 0.05$. Oneway analysis of variance (ANOVA) were used to compare the difference between colonization percentages among all the collected plants $(P \leq 0.05)$ and means was separated by least significant difference (LSD) method. All values were calculated from 10 different replicates and means were reported \pm standard error (SE). Correlation between percentages of different mycorrhizal structure and different soil chemical and physical characteristics was compared using the Pearson's correlation coefficient (R2). The different statistical tests were performed using the SPSS 21.0 statistical program "SPSS Inc., IBM" (Chicago, IL, USA).

\section{Results and Discussion}

\section{Collected plants identification}

The total number of collected plants from the two studied areas was 14 plants (Table 1), represented by 9 unique plants. Plant samples collected from each stand were identified according to (Collenette, 1999; Chaudhary, 2001) at the herbarium of King Saud University, Riyadh, Saudi Arabia. Seven different plants were collected from Riyadh and Qassim regions. However, were collected from both Riyadh and Qassim regions. Furthermore, no plants were repeated in the two studied regions. The repeated plants from Riyadh and Qassim were collected from comparisons between mycorrhizal infection of the same plants under different climatic conditions of the two areas. Collected plants 
belong to 4 unique plant families (Asteraceae, Boraginaceae, Brassicaceae and Polygonaceae).

\section{Mycorrhizal colonization}

\section{Mycorrhizal diversity}

In total, 7 out of 14 collected plants were found to be associated with different species of mycorrhizal fungi. The most abundant mycorrhizal genus in the collected samples was Glomus as it was found associated with 7 plants collected from different regions with 5 different species (Table 2). In Riyadh region, two plants (out of 7 collected; P1: P7) were found to be associated with two different mycorrhizal species, namely Glomus deserticola and Glomus geosporum. Five different plants collected from Qassim region (out of 7 collected; P8: P14) were colonized by different mycorrhizal species. Mycorrhizal species found in Qassim region were Glomus deserticola, Glomus aggregatum, Diversispora spurca, Glomus etunicatum and Glomus mosseae

\section{Phylogenetic analysis}

Phylogenetic analysis of extracted mycorrhizal DNA was performed in order to confirm the morphological identification of mycorrhizal species. Analysis was performed on the DNA sequences of the samples showed mycorrhizal colonization as described above. The obtained results confirmed the morphological identification of mycorrhizal spores. Figure 1 shows the phylogenetic tress produced by MEGA software to identify the mycorrhizal species in each collected plant. The results show that the Echium rauwolfia plants collected from Riyadh region (sample 2) and from Qassim region (sample 9) were colonized by Glomus deserticola. Pulicaria guestii plant (sample 4) collected from Riyadh region was colonized by Hypocrea lixii.
Anthemis deserti plant collected from Riyadh region (sample 5) was colonized by Hypocrea nigricans, while the same plant collected from Qassim region (sample 12) showed mycorrhizal association with Glomus etunicatum. Picris sp. plant collected from Riyadh region (sample 7) was colonized by Glomus geosporum; however, the same plant collected from Qassim region (sample 14) was colonized by Glomus mossae. Arnebia decumbens plant (sample 10) collected from Qassim region was colonized by Glomus aggregatum. Calendula arvensis plant (sample 11) collected from Qassim region were colonized by Diversispora spurca.

\section{Colonization rates and spore population}

Collected plants from the two different studied regions showed difference in mycorrhizal colonization rates (Table 3). The hyphae colonization percentage in all collected plants ranged from 66.50 to $75.00 \%$. The highest colonization percentage of $75.00 \%$ was found in Picris sp. collected from Qassim region followed by $70.00 \%$ in Picris sp. collected from Riyadh region. However, the lowest hyphae colonization was observed in Calendula arvensis $(58.11 \%)$ and Arnebia decumbens (64.22\%) plants collected from Qassim region. Vesicles colonization percentages ranged from 29.50 to $36.13 \%$. The highest colonization percentages of vesicles were found associated with Echium rauwolfia (36.13\%) plant collected from Riyadh region. Nevertheless, the lowest percentages of vesicles colonization were associated with Picris sp. (29.50\%) plants collected from Qassim region. There was a significant difference in the arbuscules colonization percentages between the different collected plants. The highest and lowest arbuscules colonization rates were found in Qassim region associated with Calendula arvensis $(60.20 \%)$ and Echium rauwolfia $(52.40 \%)$, respectively. Mycorrhizal spores 
were counted in the collected soil samples. Spore count in the rhizosphere of each collected plants were measured on the basis of $100 \mathrm{~g}$ of the samples soil. There was a great difference between spore counts in the rhizosphere of different collected plants (Table 3). Average spore counts were ranged from 105.2 to 141.5 spores/ $100 \mathrm{~g}$ of soil. The maximum spore count was found in the rhizosphere of Arnebia decumbens plant collected from Qassim region. However, the lowest spore abundance was mainly found in the soil sample collected from Riyadh region in the rhizosphere of Picris sp. (105.2 spores) and Echium rauwolfia (122.2 spores) plants.

The colonization percentages of different mycorrhizal structures and spore counts associated with the same plants collected from different two sites were compared using tTest. Echium rauwolfia plant were collected from both Riyadh (P2) and Qassim (P9) regions (Fig. 2). It was found that the plant was colonized by the same species; Glomus deserticola in both sites. Furthermore, the tTest results showed that there is no difference between colonization percentages of hyphae structures on the two plants $(P=0.83)$. However, there was a significant difference between colonization percentages of vesicles $(P \leq 0.05)$ and arbuscules $(P \leq 0.01)$. Spores showed a great significant difference between the two plants $(P \leq 0.01, \mathrm{t}=5.03)$.

Similarly, Picris sp. plants were collected from both Riyadh (P7) and Qassim (P14) regions (Fig. 3). In Riyadh region, Picris sp. plant were colonized by Glomus geosporum; however, in Qassim region, it was colonized by Glomus mosseae. The t-Test results showed no significant differences $(P \leq 0.05)$ in the colonization percentages of the different structures formed by the two fungi species. However, there was a great significant difference between the spores present in the rhizosphere the two plants $(P \leq 0.01, \mathrm{t}=4.26)$.
The results obtained in this study indicated that plants grown in Riyadh and Qassim regions in Saudi Arabia have highly diverse AMF communities. In this study, we found 7 plants colonized by 5 different mycorrhizal species, dominated mainly by Glomus genus. The mycorrhizal colonization of the selected plants in this study was not studied before in different Saudi Arabia regions. However, some studies investigated mycorrhizal diversity in Riyadh region. Al-Qarawi et al., (2012) studied the mycorrhizal colonization percentages of 10 different plants, namely Calendula officinalis L., Catharanthus roseus (L.) G. Don, Convolvulus arvensis L., Cynodondactylon (L.) Pers., Petunia hybrida (L.) Mill. Gaillardia pulchella Foug., Ocimum sanctum L., Phoenix dactylifera L., Sesuvium portulacastrum (L.) L., Tagetes patula L. They found that the highest infection was recorded in Petunia hybrida and Gaillardia pulchella (97\%) followed by Calendula officinalis (90\%) and Cynodon dactylon (87\%); however, the lowest infection was found in Sesuvium portulacastrum (33\%). The maximum vesicles were found in $P$. hybrida (97\%) followed by $G$. pulchella $(80 \%)$ and $C$. officinalis $(67 \%)$, and the minimum was found in $P$. dactylifera (7\%). The highest colonization percentage of arbuscules was recorded with $P$. hybrida $(73 \%)$ and arbuscules were not found with $C$. arvensis, $S$. portulacastrum. Furthermore, the highest number of spores was recorded from the rhizosphere soils of $P$. hybrida and the lowest number was found with $S$. portulacastrum. Moreover, Khaleil (1989) studied the mycorrhizal colonization associated with Anisosciadium lanatum, Korwoodia dicksoniae, Tripleurospermum auriculatum, Anthemis deserti, Rhazyastricta and Panicum turgidum in Riyadh region and found that two different species of AMF, namely Glomus fasciculatum and G. mosseae associated with these plants. 
Table.1 The different studied plants and their families and location

\begin{tabular}{|l|l|l|l|}
\hline No. & Plant & Family & Location \\
\hline $\mathbf{1}$ & Rumexvesicarius & Polygonaceae & Riyadh \\
\hline $\mathbf{2}$ & Echiumrauwolfia & Boraginaceae & Riyadh \\
\hline $\mathbf{3}$ & Zilla spinose & Brassicaceae & Riyadh \\
\hline $\mathbf{4}$ & Pulicariaguestii & Asteraceae & Riyadh \\
\hline $\mathbf{5}$ & Anthemis deserti & Asteraceae & Riyadh \\
\hline $\mathbf{6}$ & Erucariahispanica & Brassicaceae & Riyadh \\
\hline $\mathbf{7}$ & Picris sp. & Asteraceae & Riyadh \\
\hline $\mathbf{8}$ & Rumexvesicarius & Polygonaceae & Qassim \\
\hline $\mathbf{9}$ & Echiumrauwolfia & Boraginaceae & Qassim \\
\hline $\mathbf{1 0}$ & Arnebiadecumbens & Boraginaceae & Qassim \\
\hline $\mathbf{1 1}$ & Calendula arvensis & Asteraceae & Qassim \\
\hline $\mathbf{1 2}$ & Anthemis deserti & Asteraceae & Qassim \\
\hline $\mathbf{1 3}$ & Erucariahispanica & Brassicaceae & Qassim \\
\hline $\mathbf{1 4}$ & Picris sp. & Asteraceae & Qassim \\
\hline
\end{tabular}

Table.2 The diversity of mycorrhizae in studied plants

\begin{tabular}{|l|l|}
\hline Sample No. & Mycorrhiza Species \\
\hline P2 & Glomus deserticola \\
\hline P7 & Glomus geosporum \\
\hline P9 & Glomus deserticola \\
\hline P10 & Glomus aggregatum \\
\hline P11 & Diversisporaspurca \\
\hline P12 & Glomus etunicatum \\
\hline P14 & Glomus mosseae \\
\hline
\end{tabular}

Table.3 Colonization percentage (\%) and spore count (/ $100 \mathrm{~g}$ soil) of different mycorrhizal structures in the studied plants

\begin{tabular}{|c|c|c|c|c|}
\hline \multirow[t]{2}{*}{ Plant } & \multicolumn{4}{|c|}{ Mycorrhizal Structures } \\
\hline & Hyphae & Vesicles & Arbuscules & Spores \\
\hline $\mathbf{P 2}$ & $68.33 \pm 2.37^{*}$ & $36.13 \pm 1.08$ & $57.10 \pm 1.22$ & $122.2 \pm 2.26$ \\
\hline P7 & $70.00 \pm 1.52$ & $33.00 \pm 1.84$ & $53.70 \pm 2.12$ & $105.2 \pm 1.31$ \\
\hline P9 & $67.89 \pm 1.07$ & $33.00 \pm 0.85$ & $52.40 \pm 0.92$ & $137.4 \pm 2.00$ \\
\hline P10 & $64.22 \pm 1.41$ & $34.38 \pm 1.11$ & $56.20 \pm 0.84$ & $141.5 \pm 2.74$ \\
\hline P11 & $58.11 \pm 1.68$ & $35.63 \pm 1.23$ & $60.20 \pm 0.65$ & $122.8 \pm 1.60$ \\
\hline $\mathbf{P 1 2}$ & $68.22 \pm 3.27$ & $34.88 \pm 2.87$ & $54.40 \pm 5.38$ & $128.7 \pm 1.84$ \\
\hline P14 & $75.00 \pm 0.83$ & $29.50 \pm 0.70$ & $53.10 \pm 0.98$ & $121.0 \pm 3.46$ \\
\hline
\end{tabular}

*Values are expressed as mean of 10 replicates \pm standard error. 
Fig.1 Phylogenic analysis of the different sequenced mycorrhizal fungi
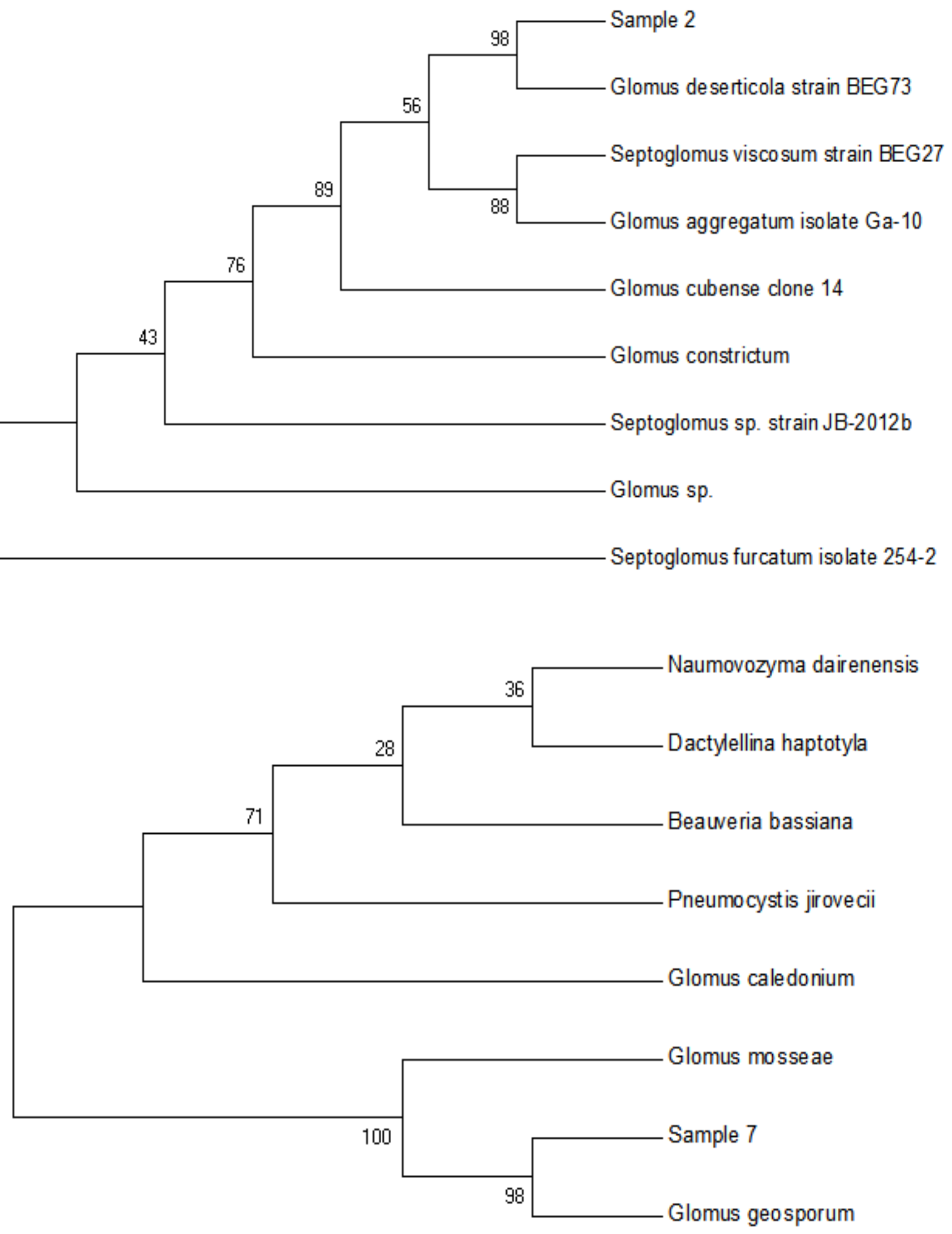

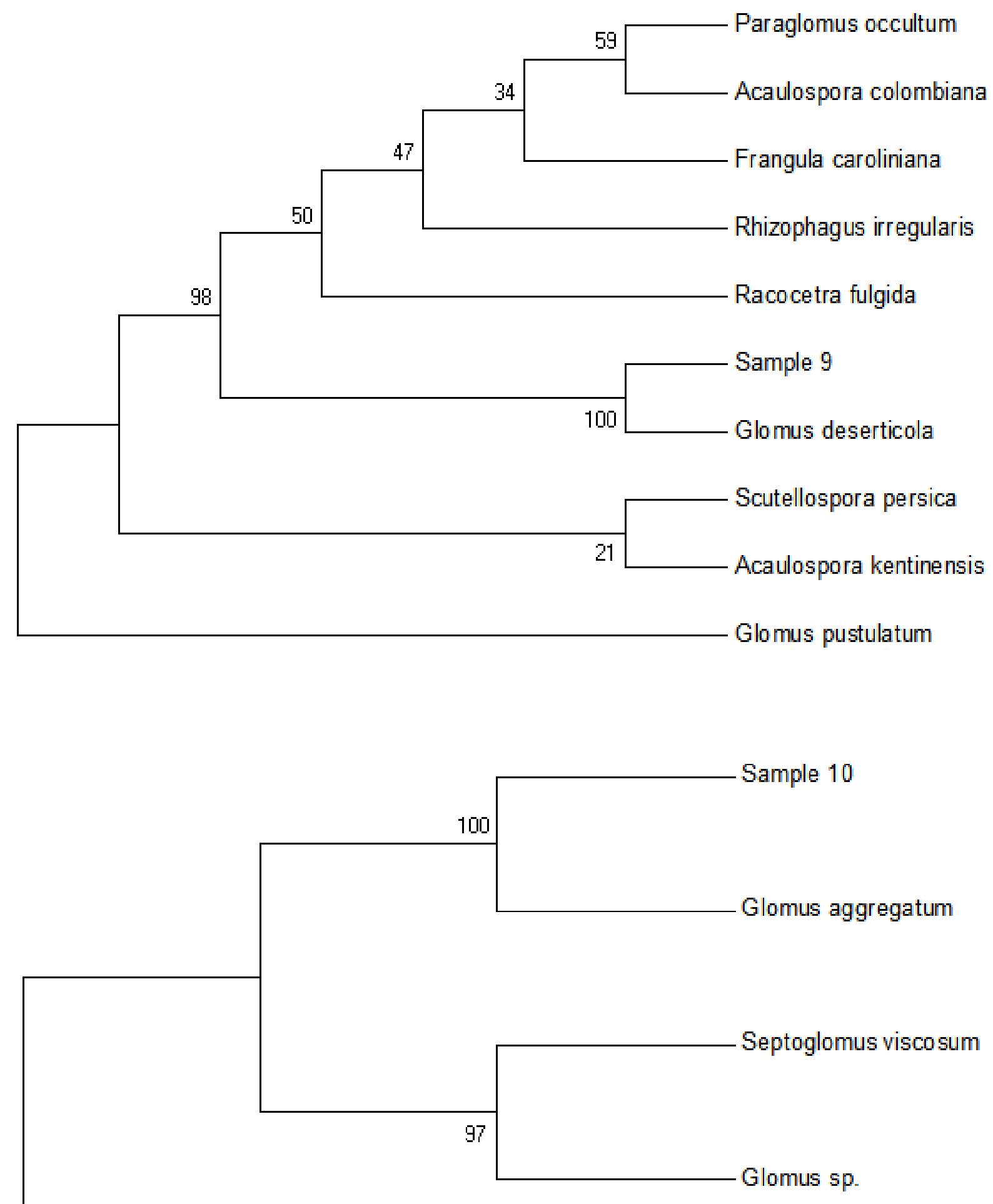

Glomus viscosum 

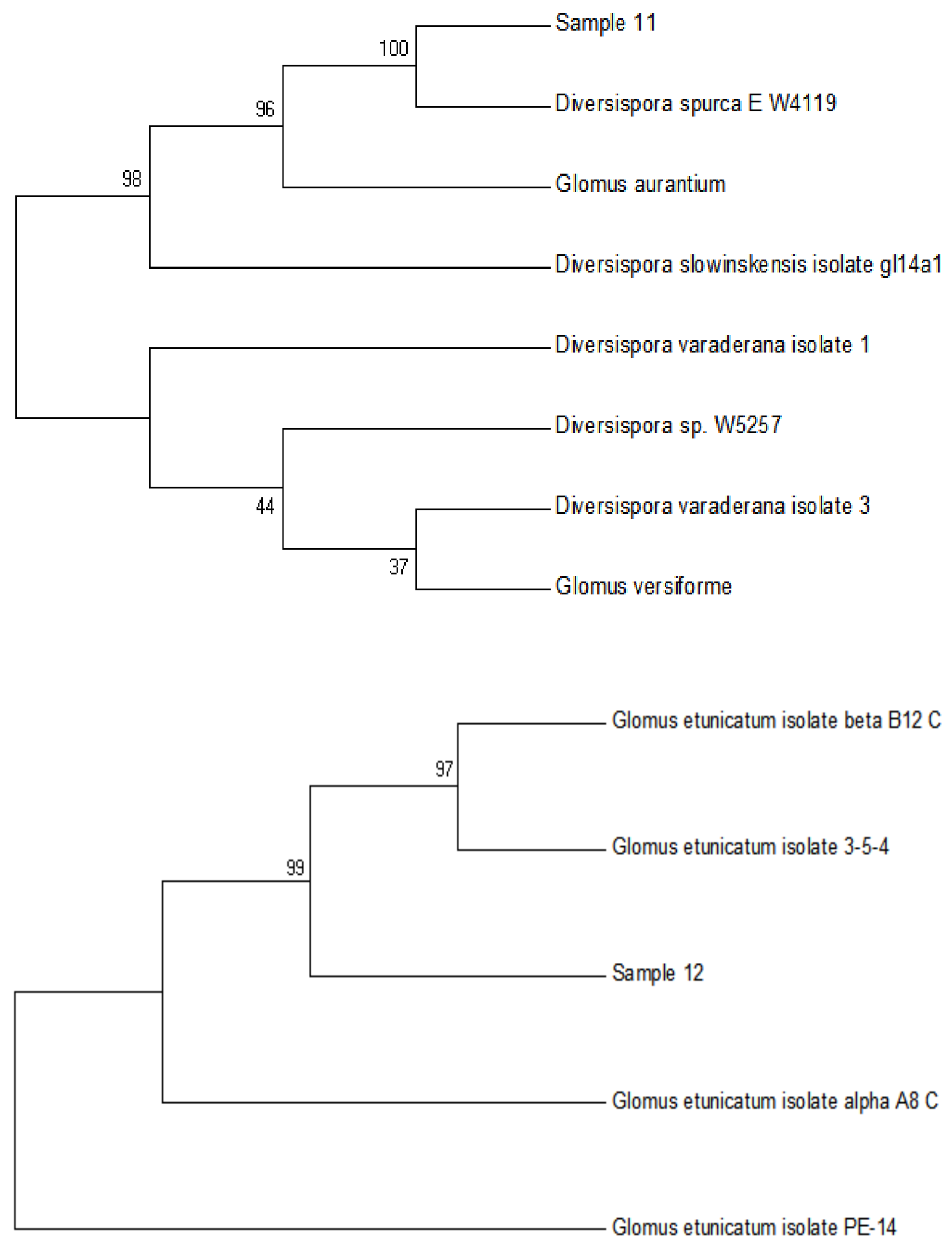


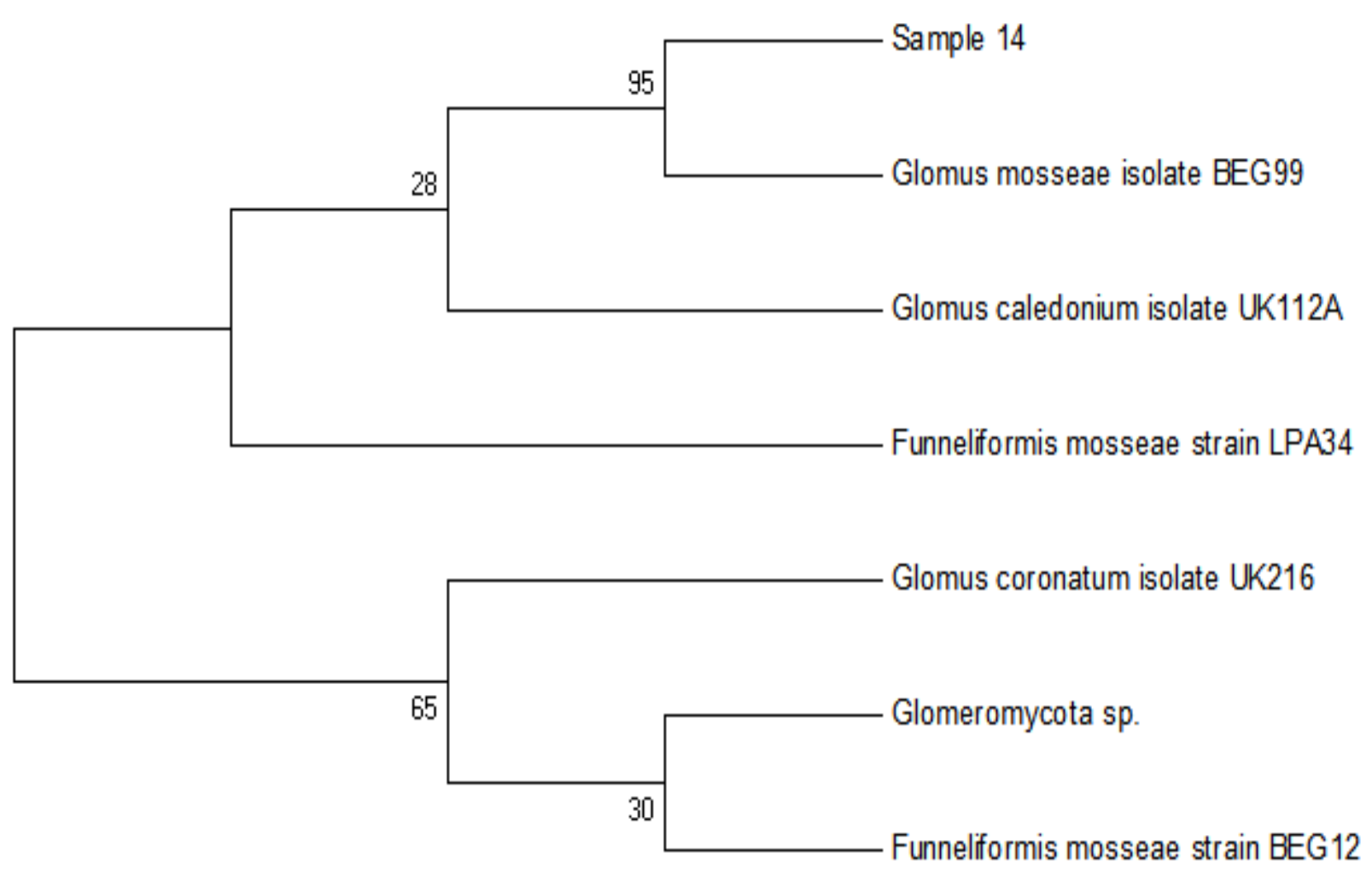

Fig.2 Difference in colonization rates (\%) of hyphae, vesicles and arbuscules and spore counts (per $100 \mathrm{~g}$ soil) associated with Echium rauwolfia collected from Riyadh (P2) and Qassim (P9)

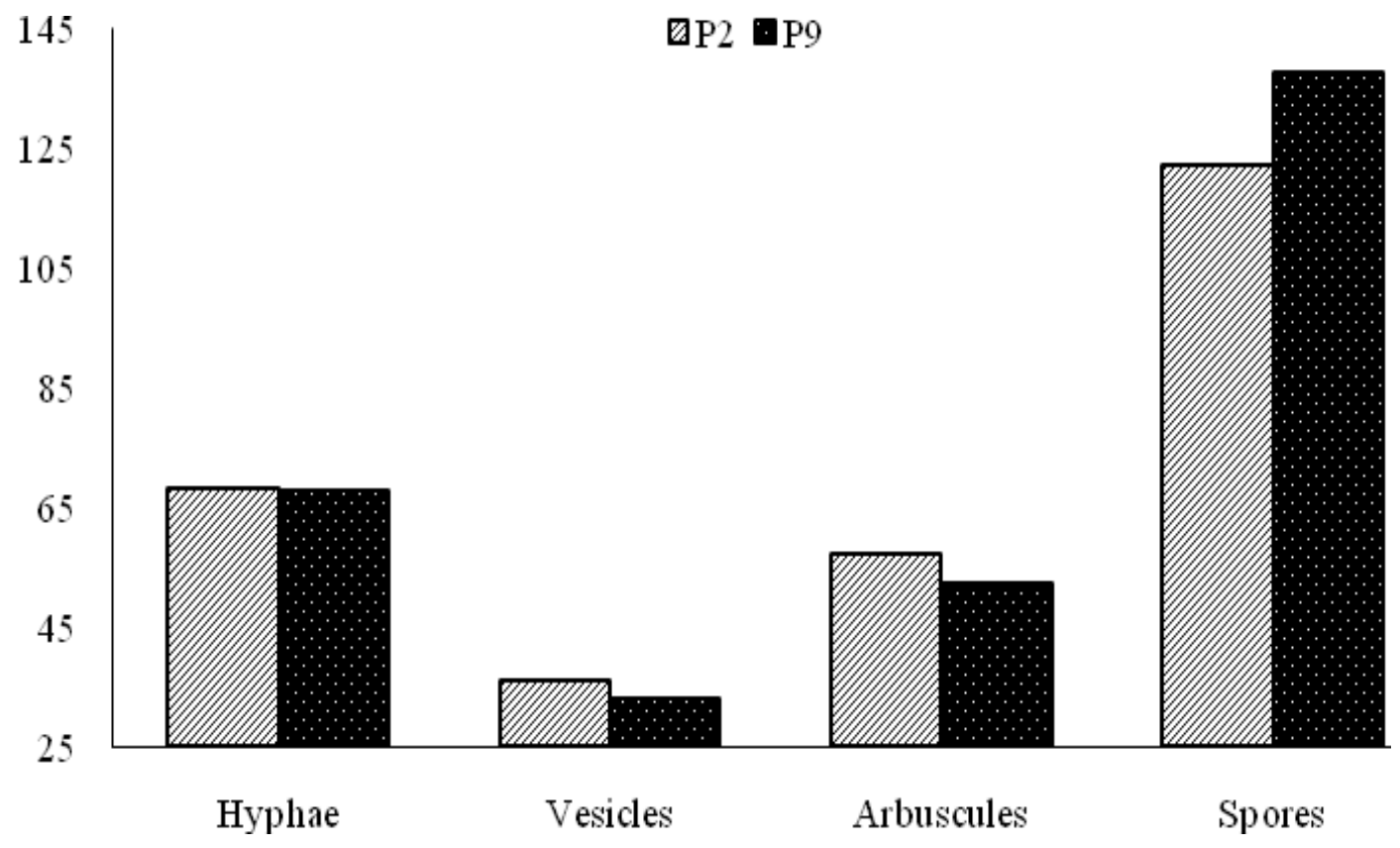


Fig.3 Difference in colonization rates (\%) of hyphae, vesicles and arbuscules and spore counts (per $100 \mathrm{~g}$ soil) associated with Picris sp. collected from Riyadh (P7) and Qassim (P14)

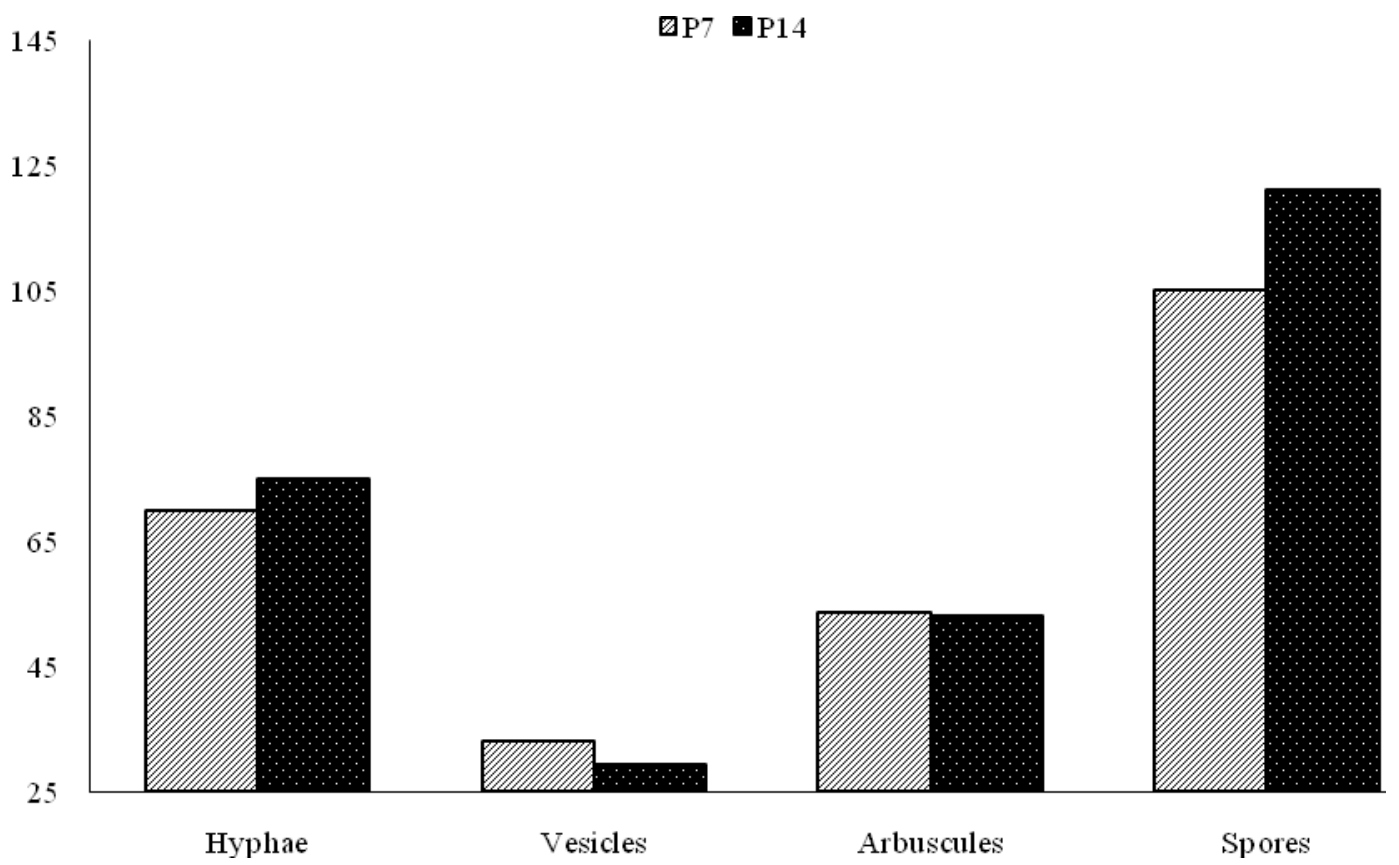

He attributed the dominance of G. mosseae to the high alkalinity of the soil. In Qassim region, AMF reported to be associated with date palms (Khaleil and Abu-Heilah, 1985). Moreover, several reports indicated the presence of AMF in different regions of Saudi Arabia but without studying the colonization percentages of different mycorrhizal structures. In western region of Saud Arabia, mycorrhizal presence was reported in Medina, Heda-Alsham and Taif (Malibari et al., 1990). The different mycorrhizal species found in the studied regions includeGlomus mosseae, Glomus fasciculatum, Gigaspora sp., Sclerocysts sp. However, Glomus species were the most dominant. The highest root infection percentage was found in the roots of alfalfa, millet and sudangrass plants. Similarly, Al-Garni and Daft (1990) studied the mycorrhizal occurrence in agricultural soils in Saudi Arabia and found six different mycorrhizal species belong to Glomus genus associated with maize and onion plants. Moreover, several studies examined the presence of mycorrhizal species in different regions of Saudi Arabia (Bahabail, 1996; AlGarni, 2001; Al-Qarawi and Al-Shahrani, 2010).

Several plants collected in this study did not show any mycorrhizal colonization. These plants include Rumex vesicarius, Zilla spinosa, Erucaria hispanica, Minuartia filifolia, Sisymbrium orientale and Argemone ochroleuca. Rumex vesicarius is a member of Polygonaceae plant family. Several studies indicated that Polygonaceae plants do not form any mycorrhizal symbiosis. Pendleton and Smith (1983) studied the status of mycorrhizal colonization of different plants at several disturbed sited in Utah, USA and found that Polygonaceae plants did not show any mycorrhizal symbiosis. Moreover, in British Columbia, different plants belong to this family did not show any mycorrhizal colonization (Berch et al., 1988). Another study surveyed the mycorrhizal colonization of Hawaiian angiosperms and found no 
colonization in plants of Polygonaceae family (Koske et al., 1992). In the tropical plains of Tamil Nadu in India, mycorrhizal fungi did not colonize any of the Polygonaceae plants (Ragupathy and Mahadevan, 1993). Furthermore, plants belonging to Polygonaceae family collected from southern Poland did not show any colonization with AMF (Pawlowska et al., 1997). Cripps and Leslie (2005) studied the distribution of mycorrhizal types among Alpine vascular plant families on the Beartooth plateau, Rocky mountains, USA and found that Polygonaceae plants had no mycorrhizal colonization.

Zilla spinosa, Erucaria hispanica and Sisymbrium orientale belonging to Brassicaceae families. It was well established that plants of Brassicaceae family do not form mycorrhizal symbiosis. Hirrel et al., (1978) approved that Brassicaceae plants do not form any mycorrhizal symbiosis. Harley and Harley (1987) studied that mycorrhizal status of most of plants in the British flora and found that mycorrhizal colonization did not occur with Brassicaceae plants. Moreover, plants belonging to Brassicaceae family did not show any infected roots with AMF (Khan and Belik, 1995). Demars and Boerner (1996) studied the arbuscular mycorrhizal development in the Brassicaceae in relation to plant life span and found no mycorrhizal colonization with most of plants belonging to this plant family.

Minuartia filifolia is one of Caryophyllaceae plants. Several earlier reports stated that Caryophyllaceae plants do not form AMF colonization (Harley and Harley, 1987; Berch et al., 1988; Pawlowska et al., 1997). Alpine plants in the Northwestern Caucasus belonging to this family did not show any mycorrhizal colonization (Onipchenko and Zobel, 2000). Furthermore, in the Patagonian steppe, Argentina, Caryophyllaceae plants had no mycorrhizal colonization (Fontenla et al., 2001). Recently, Cripps and Leslie (2005) found that Caryophyllaceae plants growing in Beartooth Plateau, Rocky Mountains, USA do not form any symbiotic relationships with mycorrhizal fungi. Similarly, Argemone ochroleuca is one ofthe plants belonging to Papaveraceae family, formerly known as Fumariaceae. Plants of this family were reported not to form mycorrhizal symbiosis (Pendleton and Smith, 1983; Harley and Harley, 1987; Berch et al., 1988). Brundrett and Kendrick (1988) investigated the mycorrhizal status of different plants grown in a sugar maple forest and found no colonization in plants belonging to Papaveraceae family.

In our study, fungi were identified using morphological and molecular characteristics. In 2011, a group of mycologists meet to evaluate six DNA regions (SSU, LSU, ITS, RPB1, RPB2, MCM7) and nominate the official fungal barcode, the ITS region, which was later approved by the Consortium for the Barcode of Life. Schoch et al., (2012) found the ITS region to be among the markers with highest probability of correct identifications for a very broad group of sampled fungi. Additional fungal studies have provided support for the ITS region as a suitable fungal barcode (Seena et al., 2010; Dentinger et al., 2011; Kelly et al., 2011). Moreover, most environmental surveys (metagenomic studies) of fungi are using the ITS region in their studies (e.g. O'Brien et al., 2005; Bellemain et al., 2010; Henrik Nilsson et al., 2011; Hibbett et al., 2011) to identify fungi using modern sequencing technology, such as nextgeneration sequencing, which can aid in rapid identification of fungi without the need to clone the amplicons. This sequencing approach has therefore created a surge in the number of ITS sequences that are available in GenBank (Seifert, 2009; Begerow et al., 2010). According to Schoch et al., (2012), 
currently about 172,000 full-length fungal ITS sequences are deposited in GenBank, of which $56 \%$ have a Latin binomial associated, representing approximately 2500 genera and 15,500 species. The ITS region is a useful barcode marker because it usually can be sequenced from previously described fungi for which no sequence data are currently available by sequencing the type material (i.e., the specimen on which a species is originally described and deposited in a fungarium). Therefore, the practicality and broad kingdom-wide taxonomic applicability make ITS a useful tool for fungal barcoding for most ( $\sim 70 \%$ of all fungi tested) (Schoch $e t$ al., 2012; Yahr et al., 2016) if not all lineages of fungi (Nilsson et al., 2008; Seifert, 2009; Vrålstad, 2011; Kiss, 2012).

Spore population in the rhizosphere of the collected samples was calculated in this study as the number of spores present in 100 grams of soil rhizosphere. Spore population associated with some plants grown in Riyadh region was reported (Al-Qarawi et al., 2012). It was found that spores count ranged from 59 to 216 spore per 100 grams of dry soil. Moreover, the highest number of spores was recorded from the rhizosphere soils of $P$. hybrida and the lowest number was found with S. portulacastrum. Al-Garni (2001) reported a wide variation among the samples for spore populations with the field soils and infectivity of AMF with roots from a study on Taif soils and standing crops. On the other hand, several studies reported occurrence and diversity of mycorrhizae in desert plants (Miller, 1979; Rose, 1981; Mejstř́k and Cudlín, 1983; Stutz and Morton, 1996; He et al., 2002; Titus et al., 2002; Chaudhry et al., 2006; Panwar and Tarafdar, 2006; Uhlmann et al., 2006) but very few references are available with structural colonization studies and spore population in different countries with desert plants especially from Saudi Arabia.

\section{References}

Al-Garni, S. M. (2001). Effect of seasonal variations on mycorrhizal occurrence and influence of salinity stress on maize and cowpea infected by Mycorrhiza and their activities in host plants. Delta Journal of Science, 25, 1-9.

Al-Garni, S. M., and Daft, M. J. (1990). Occurrence and effectiveness of vesicular arbuscular mycorrhizas in agricultural soils from Saudi Arabia. Biol Agric Hortic., 7, 69-80.

Al-Qarawi, A. A., and Al-Shahrani, T. (2010). Growth response of two species of zizyphus to inoculation with arbuscular mycorrhizal fungi. Journal of King Abdulaziz University: Metrology, Environment and Arid Land Agricultural Sciences, 21, 109-122.

Al-Qarawi, A. A., Mirdha, M. A. U., and Alghamdi, O. M. (2012). Diversity of Structural Colonization and Spore Population of Arbuscular Mycorrhizal Fungi in Some Plants from Riyadh, Saudi Arabia. J Pure Appl Microbiol., 6, 1119-1125.

Al-Whaibi, M. A. (2009). Desert plants and mycorrhizae (a mini-review). J Pure Appl Microbiol., 3, 457-466.

Apple, M. E. (2010). Aspects of Mycorrhizae in Desert Plants. In "Desert Plants: Biology and Biotechnology" (K. G. Ramawat, ed.), pp. 121-134. Springer Berlin Heidelberg, Berlin, Heidelberg.

Bahabail, A. S. (1996). Studies on VA mycorrhiza in soil of Taif province, King Abdulaziz University, Saudi Arabia.

Begerow, D., Nilsson, H., Unterseher, M., and Maier, W. (2010). Current state and perspectives of fungal DNA barcoding and rapid identification procedures. Appl Microbiol Biotechnol., 87, 99-108.

Bellemain, E., Carlsen, T., Brochmann, C., Coissac, E., Taberlet, P., and Kauserud, 
H. (2010). ITS as an environmental DNA barcode for fungi: an in silico approach reveals potential PCR biases. BMC Microbiol., 10, 189.

Berch, S. M., Gamiet, S., and Deom, E. (1988). Mycorrhizal status of some plants of southwestern British Columbia. Can J Bot., 66, 1924-1928.

Brundrett, M. C., and Kendrick, B. (1988). The mycorrhizal status, root anatomy, and phenology of plants in a sugar maple forest. Can J Bot., 66, 11531173.

Chaudhary, S. A. (2001). "Flora of the Kingdom of Saudi Arabia," Ministry of Agriculture and Water, Riyadh.

Chaudhry, M. S., Nasim, F. H., and Khan, A. G. (2006). Mycorrhizas in the perennial grasses od Cholistan desert, Pakistan. Int J bot., 2, 210-218.

Collenette, S. (1999). "Wildflowers of Saudi Arabia," National Commission for Wildlife Conservation and Development (NCWCD), Riyadh.

Collier, S. C., Yarnes, C. T., and Peter Herman, R. (2003). Mycorrhizal dependency of Chihuahuan Desert plants is influenced by life history strategy and root morphology. J Arid Environ., 55, 223-229.

Cripps, C. L., and Leslie, H. E. (2005). Distribution of Mycorrhizal Types among Alpine Vascular Plant Families on the Beartooth Plateau, Rocky Mountains, U.S.A., in Reference to Large-Scale Patterns in Arctic-Alpine Habitats. Arct Antarct Alp Res., 37, 177188.

Demars, B. G., and Boerner, R. E. J. (1996). Vesicular arbuscular mycorrhizal development in the Brassicaceae in relation to plant life span. Flora., 191, 179-189.

Dentinger, B. T., Didukh, M. Y., and Moncalvo, J. M. (2011). Comparing COI and ITS as DNA barcode markers for mushrooms and allies (Agaricomycotina). PLoS One., 6, e25081.

Fontenla, S., Puntieri, J., and Ocampo, J. A. (2001). Mycorrhizal associations in the Patagonian steppe, Argentina. Plant Soil., 233, 13-29.

Gerdemann, J. W., and Nicolson, T. H. (1963). Spores of mycorrhizal Endogone species extracted from soil by wet sieving and decanting. Transactions of the British Mycological Society., 46, 235-244.

Harley, J. L., and Harley, E. L. (1987). A CHECK-LIST OF MYCORRHIZA IN THE BRITISH FLORA. New Phytol., 105, 1-102.

He, X., Mouratov, S., and Steinberger, Y. (2002). Temporal and spatial dynamics of vesicular-arbuscular mycorrhizal fungi under the canopy of Zygophyllum dumosum Boiss. in the Negev Desert. $J$ Arid Environ., 52, 379-387.

Helgason, T., Daniell, T. J., Husband, R., Fitter, A. H., and Young, J. P. W. (1998). Ploughing up the wood-wide web? Nature., 394, 431.

Henrik Nilsson, R., Tedersoo, L., Lindahl, B. D., Kjoller, R., Carlsen, T., Quince, C., Abarenkov, K., Pennanen, T., Stenlid, J., Bruns, T., Larsson, K. H., Koljalg, U., and Kauserud, H. (2011). Towards standardization of the description and publication of next-generation sequencing datasets of fungal communities. New Phytol., 191, 314-8.

Herrmann, L., Lesueur, D., Bräu, L., Davison, J., Jairus, T., Robain, H., Robin, A., Vasar, M., Wiriyakitnateekul, W., and Öpik, M. (2016). Diversity of rootassociated arbuscular mycorrhizal fungal communities in a rubber tree plantation chronosequence in Northeast Thailand. Mycorrhiza., 26, 863-877.

Hibbett, D. S., Ohman, A., Glotzer, D., Nuhn, M., Kirk, P., and Nilsson, R. H. (2011). 
Progress in molecular and morphological taxon discovery in Fungi and options for formal classification of environmental sequences. Fungal Biol Rev., 25, 38-47.

Hirrel, M. C., Mehravaran, H., and Gerdemann, J. W. (1978). Vesiculararbuscular mycorrhizae in the Chenopodiaceae and Cruciferae: do they occur? Can J Bot., 56, 2813-2817.

Kelly, L. J., Hollingsworth, P. M., Coppins, B. J., Ellis, C. J., Harrold, P., Tosh, J., and Yahr, R. (2011). DNA barcoding of lichenized fungi demonstrates high identification success in a floristic context. New Phytol., 191, 288-300.

Khaleil, A. S. (1989). Mycorrhizal status of some desert plants and correlation with edaphic factors. Trans Mycol Soc Japan30, 231-237.

Khaleil, A. S., and Abu-Heilah, A. N. (1985). Formation of vesicular-arbuscular mycorrhizae in Phoenix dactylifera L., cultivated in Qassim region Saudi Arabia. Pak J Bot., 17, 267-270.

Khan, A. G., and Belik, M. (1995). Occurence and Ecological Significance of Mycorrhizal Symbiosis in Aquatic Plants. In "Mycorrhiza: Structure, Function, Molecular Biology and Biotechnology" (A. Varma and B. Hock, eds.), pp. 627-666. Springer Berlin Heidelberg, Berlin, Heidelberg.

Kiss, L. (2012). Limits of nuclear ribosomal DNA internal transcribed spacer (ITS) sequences as species barcodes for Fungi. Proc Natl Acad Sci U S A109, E1811; author reply E1812.

Koske, R. E., Gemma, J. N., and Flynn, T. (1992). Mycorrhizae in Hawaiian Angiosperms: A Survey with Implications for the Origin of the Native Flora. Am J Bot., 79, 853-862.

Maček, I., Šibanc, N., Kavšček, M., and Lestan, D. (2016). Diversity of arbuscular mycorrhizal fungi in metal polluted and EDTA washed garden soils before and after soil revitalization with commercial and indigenous fungal inoculum. Ecol Eng., 95, 330-339.

Malibari, A. A., Al-Fassi, F. A., and Ramadan, E. M. (1990). Studies on vesicular arbuscular mycorrhizas of the western region soil, Saudi Arabia. Ann Agric Sci., 35, 95-111.

Mejstř́k, V. K., and Cudlín, P. (1983). Mycorrhiza in some plant desert species in Algeria. Plant Soil., 71, 363-366.

Miller, R. M. (1979). Some occurrences of vesicular-arbuscular mycorrhiza in natural and disturbed ecosystems of the Red Desert. Can J Bot., 57, 619-623.

Nilsson, R. H., Kristiansson, E., Ryberg, M., Hallenberg, N., and Larsson, K. H. (2008). Intraspecific ITS variability in the kingdom fungi as expressed in the international sequence databases and its implications for molecular species identification. Evol Bioinform Online4, 193-201.

O'Brien, H. E., Parrent, J. L., Jackson, J. A., Moncalvo, J. M., and Vilgalys, R. (2005). Fungal community analysis by large-scale sequencing of environmental samples. Appl Environ Microbiol., 71, 5544-50.

Onipchenko, V. G., and Zobel, M. (2000). Mycorrhiza, Vegetative Mobility and Responses to Disturbance of Alpine Plants in the Northwestern Caucasus. Folia Geobot35, 1-11.

Panwar, J., and Tarafdar, J. C. (2006). Distribution of three endangered medicinal plant species and their colonization with arbuscular mycorrhizal fungi. J Arid Environ., 65, 337-350.

Pawlowska, T. E., Błaszkowski, J., and Rühling, A. (1997). The mycorrhizal status of plants colonizing a calamine spoil mound in southern Poland. Mycorrhiza., 6, 499-505. 
Pendleton, R. L., and Smith, B. N. (1983). Vesicular-Arbuscular Mycorrhizae of Weedy and Colonizer Plant Species at Disturbed Sites in Utah. Oecologia., 59, 296-301.

Ragupathy, S., and Mahadevan, A. (1993). Distribution of vesicular-arbuscular mycorrhizae in the plants and rhizosphere soils of the tropical plains, Tamil Nadu, India. Mycorrhiza., 3, 123 136.

Rose, S. L. (1981). Vesicular-arbuscular endomycorrhizal associations of some desert plants of Baja California. Can J Bot., 59, 1056-1060.

Schoch, C. L., Seifert, K. A., Huhndorf, S., Robert, V., Spouge, J. L., Levesque, C. A., and Chen, W. (2012). Nuclear ribosomal internal transcribed spacer (ITS) region as a universal DNA barcode marker for Fungi. Proc Natl Acad Sci U S A., 109, 6241-6.

Seena, S., Pascoal, C., Marvanová, L., and Cássio, F. (2010). DNA barcoding of fungi: a case study using ITS sequences for identifying aquatic hyphomycete species. Fungal Divers44, 77-87.

Seifert, K. A. (2009). Progress towards DNA barcoding of fungi. Mol Ecol Resour., 9, 83-89.

Simon, L., Lalonde, M., and Bruns, T. D. (1992). Specific amplification of $18 \mathrm{~S}$ fungal ribosomal genes from vesicular- arbuscular endomycorrhizal fungi colonizing roots. Appl Environ Microbiol., 58, 291-295.

Smith, S. E., and Read, D. (2008). 8 - Growth and carbon allocation of ectomycorrhizal symbionts. In "Mycorrhizal Symbiosis (Third Edition)", pp. 295-320. Academic Press, London.

Stutz, J. C., and Morton, J. B. (1996). Successive pot cultures reveal high species richness of arbuscular endomycorrhizal fungi in arid ecosystems. Can J Bot., 74, 1883-1889.

Titus, J. H., Titus, P. J., Nowak, R. S., and Smith, S. D. (2002). Arbuscular Mycorrhizae of Mojave Desert Plants. West N Am Nat., 62, 327-334.

Uhlmann, E., Görke, C., Petersen, A., and Oberwinkler, F. (2006). Arbuscular mycorrhizae from arid parts of Namibia. J Arid Environ., 64, 221-237.

Vrålstad, T. (2011). ITS, OTUs and beyondfungal hyperdiversity calls for supplementary solutions. Mol Ecol., 20, 2873-2875.

Yahr, R., Schoch, C. L., and Dentinger, B. T. M. (2016). Scaling up discovery of hidden diversity in fungi: impacts of barcoding approaches. Philosophical Transactions of the Royal Society B: Biological Sciences., 371.

\section{How to cite this article:}

Fahad S. Albaqami, Saleh A. Sohaibani and Murugan Kasi. 2018. Arbuscular Mycorrhizal Fungi Diversity in Two Different Regions in Saudi Arabia. Int.J.Curr.Microbiol.App.Sci. 7(04): 2492-2510. doi: https://doi.org/10.20546/ijcmas.2018.704.286 